\title{
Research on Plant Landscape Planning of Daming Palace National Heritage Park of Xi'an
}

\author{
Jie Wang \\ Xi’an International University, Xi’an, 710077, China
}

Keywords: Daming Palace National Heritage Park, Plant landscape, Disposing and landscaping

\begin{abstract}
Xi'an is one of the main cities of large sites in China, and the Daming Palace site is the most representative large site resource in Xi'an. Based on the built-up Daming Palace National Heritage Park, the researcher did a comprehensive survey and analysis of the types selection, configuration and landscape, space separation and connection of plant in the Daming Palace from the perspective of plant landscape planning, put forward and expound the planning idea of "Three Rings, One Axis and Multiple Zones”. It is hoped that it can provide a feasible reference for the plant landscape planning of other urban sites parks.
\end{abstract}

General secretary Xi Jinping put forward the strategy of construction of "The Belt and Road", gives the new connotation of the times for the ancient Silk road. As the starting point of the ancient Silk Road, Xi'an was once again standing on the new starting point of the "Silk Road Economic Belt". According to the "Xi'an construction Silk Road Economic Belt (New Start) strategic planning" of Xi'an "historical and cultural characteristics of the international metropolis" positioning, reflects the inheritance and protection of the historical context of Xi'an, "the historical monuments and cultural relics" as the name card of Xi'an, into the soft power of city competition.

Xi'an is one of the main city in China remains concentrated in 2005, Xi'an Han Changan ruins, ruins of Daming Palace of Tang Dynasty, Epang palace ruins, Jiangzhai site and Han Du Mausoleum ruins, is the State Administration of cultural heritage included in the "11th Five-Year" 100 big relics protection plan. These 5 big sites are all world class. The large site resources of Xi'an are worldwide and unique.

How in the rapid economic development, to protect and use of the site effectively, scientific and rational planning of the park site, the construction of "cultural tourism center" to lay the Silk Road culture brand, is the important significance of Xi'an big relics protection and development. In this paper, the Daming Palace Ruins Park as an example, starting from the angle of plants in order to explore a new way, site protection and landscape planning.

\section{Basic Situations}

Daming Palace Ruins Park is located in Xi'an City Taihua Road, located in the northern part of Xi'an on the outside of the original, approximately 3.2 square kilometers, the perimeter wall nearly 8000 meters, was built in 634 years, was the center of political and national symbol. The current proven range and the general shape of Miyagi, a 9 seat exploration palace ruins, 37 building sites and most Palace ruins. In June 2007, the Xi'an Municipal People's government formally launched the comprehensive project of the protection of the Daming Palace site and the surrounding environment transformation. It was built in October 1, 2010 and opened to the outside world in the way of ruins park. The landscape space layout of "one axis, three zone", a shaft from the south to the north through the door, the house with the Danfeng, Nobumasa Dian, shishinden and Tai Chi of the central axis, three zones is the palace area as the center of the Danfeng gate to the house with the temple area, to the house with the Nobumasa, temple, shishinden as the center of the palace area, and the ether liquid pool.

In 1957 the Daming Palace Ruins Protection is incorporated into the overall development plan of 
Xi'an City, from the beginning of 2007, in order to solve the increasingly sharp contradiction between Xi'an city and the process of the Daming Palace Ruins Protection, the formation of city ruins and harmony development situation, Xi'an municipal government officially launched the construction of Daming Palace Ruins Park, Daming Palace Ruins to 2010 the park was formally completed and opening up.

\section{Current Situations Survey of Greening Landscape}

Overall, the Daming Palace Ruins Park in addition to building and repair the pier base outside the museum to the basic theme of open green space in the form of green space, according to the needs of the show area planning buildings, sculptures. Between the door and the house with the Danfeng square, in order to maintain the open space to form a large historical landscape atmosphere, the tall tree and plant planting ranks as the main body of the ground, hard wooden inlaid stone, no shrubs and ground cover plants, in order to identify central garden for the site; the axis on both sides of the different areas of the site, with the cold season turf covered with trees and shrubs to create a display space.

In the house with the southern part of the space is not large trees and cover, even with Shi Nan, this tree Ligustrum was also become the tall hedge pruning scale ball, to set off the house with the building of the tall pier foundation. And the pine cypresses on both sides of the temple are as if to guard the remains of the yuan hall, and use the pine and cypress to highlight the solemnity of the whole palace.

The house with the north to the south of the Tai Chi, the palace area with a dense building site landscape, basic to the turf coverage, plant species on the two sides of the axis park is not much, the Shochiku, tree for trees, with a plum, sweet scented osmanthus flowering shrub embellishment. Until near the liquid pool, only relatively more abundant species. Tai Chi of the part of the south by undulating terrain, the hedge pruning into clumps to block the line of sight of people, the formation of scenery. Along the Hunan Road Department has a Phyllostachys plexus, growing strong. Tai Chi of the area to the north lake willow plants, Hedgerow for Ligustrum quihoui cut into a certain shape, the lake on the island in addition to plant chinaberry, osmanthus, ginkgo, apricot, loquat trees and crabapple, Acer palmatum, crape myrtle, and bloom so iaccio boxwood, privet, hibiscus, Nandina, red wood, ten merit shrub plant level relatively rich.

Division of palace area axis on both sides of the peony garden, Juyuan, plum, pear, apricot, persimmon garden and other large parks, to reproduce the planting year of garden plants. Based on archaeological and historical research, the Daming Palace Ruins Park mostly restored the landscape at that time based on archaeological and historical research. The original tree varieties were preserved as much as possible. According to incomplete statistics, there are trees of Pinus tabulaeformis, apricot, willow, metasequoia, Sophora japonica, Shi Nan, loquat, persimmon, hawthorn, Chinese catalpa, poplar, Melia azedarach, ginkgo and other 13 kinds of shrubs, a sweet scented osmanthus, plum, pear, crabapple, Malus halliana, Acer palmatum, Nandina, ten, work Pittosporum, Ligustrum quihoui, hibiscus, crape myrtle, Euonymus japonicus, Cornus alba, Phyllostachys, procumbent juniper 17, by comparison of a single plant, only an evergreen turf. The park main tree species in Sophora japonica and Ligustrum quihoui, on the island of South Main bamboo bush.

\section{Existing Problems and Disadvantages}

\subsection{Disadvantage of Plant Beautifying and Hierarchical Collocation}

The limited plant species, but species planted around the liquid pool is relatively rich, the large area basically only trees and grass covered, rare flowering shrubs. Although to protect the body site area, planting large trees in limited quantities, but the whole park plant obviously inadequate in quantity and type is relatively single, the formation of art and hierarchical structure of plants is not well reflected, from the level of space to the vertical space between plants, the transition is blunter, 
the lack of plant landscape and configuration of beauty.

\subsection{Single Color of Plant}

The whole Daming Palace is dominated by deciduous tree species and lacks the collocation of evergreen and color leaf irrigated plants. After winter basic green, seasonal changes of plants are not obvious. Part of the region, although the planting of flower shrubs is insufficient, and relatively low. The same plant patches are often used in different regions, leading to the monotonous landscape of these regions. The use of foliage plants is less in the whole garden, especially for local sketches, sculptures and other landscapes, which do not make good use of plant communities and leaf color changes to match the local landscape to achieve the effect of spot. There is a lack of regional and humanistic characteristics of plant landscape.

\subsection{Disadvantage of Plant Spatial Organization and Partition}

The site is too open, the planting density of the regional plants is low, and the transition, separation and enclosure of shrubs and ground cover plants are lacking. In addition to the construction site, the green space is not well utilized. The organization and division of the plant space make the green plots relatively loose, and the relationship between them is poor. The overall green space lacks the change of opening and closing. There is also a lack of emphasis and effective foil to the themes of the regions that need to be displayed.

\subsection{Disadvantage of Plant Cultivation and Density and lack of Softening and Humanized Space}

For the corner part of buildings and roads of the lack of softening and softening treatment, for the nearby bare landscape and exposed the bad pieces of loess ground lack of shielding effect. Some trails and visitors rest area planting trees lack of volume, lack of shading effect, lack of rest facilities tour route, the rest seat or seat completely exposed to the edge of the lawn, the lack of plant configuration, isolation and shading, not to swim people create a comfortable rest environment, and for planning the plant park, although larger plants due to the smaller volume, larger space is regional plant comparative alienation, lack of ornamental value.

\section{Path Research on Plant Landscape Planning}

Daming Palace Ruins whether it is used in the protection of historical and cultural city center or modern green space has important value, as the site must be developed and use scientific and reasonable under the premise of protection, the Xi'an municipal government will be the Daming Palace Ruins Park in the form of open to the people, as the city center green. In landscape planning and planning of city park or green space in general, plant planning must consider the carrying capacity and ecological site sensitivity, can also reflect the regional characteristics and culture must consider the sustainable development.

\subsection{Adopt Planning Idea of “Three Rings, One Axis and Multiple Zones” on the Whole}

Outside the venue is the site boundary area planting hedgerow and woodland formed a natural Wai green belt, to separate the city noisy environment, the public can penetrate the open woodland park; park in the main loop, species and quantity based on the original trees planted in rich planting trees. Can choose the specifications of the seedlings can be planted to meet canopy coverage, has some other shrubs formed certain rhythm and enclosure and barrier can be site between the loop tree; the Third Ring Road near the liquid pool, within the ring road and regional construction sites far distance can be widely carried out planting and configuration of plants, the formation of the core landscape. The axial region can choose evergreen shrubs such as Osman thus or heather (below 1.5 meters) from south to north along the axis of the plant, forming a rigorous pattern, the internal ring area according to the protection of the site selection of shallow root planting shrubs and ground vegetation division and planting, to ensure that the four seasons are green, three flowering seasons. The green landscape of the ruins park is improved. 


\subsection{Enrich Community Landscape and Increase Color Composition in Some Portions}

For the sparse planting area of the original site, the principles of proper planting and planting were combined with the description of plant species in Daming Palace in historical documents, and the rich landscape level was formed by collocation of plants of Joe, irrigation and grass. For areas suitable for planting tall trees, the number and species of trees can be replenishing, especially for plants in the vertical direction. For the areas that are not suitable for planting trees, the collocation and landscaping of species rich shrubs and ground cover plants should be emphasized. Considering the variety of plant collocation and color, in addition to the original tree in Sophora japonica and sycamore, Magnolia, cherry, can enrich the Koelreuteria paniculata, Prunus cerasifera, wood, silk silk, shrubs can increase planting flowering plum, red wood, clove, Bauhinia, Tang Di, winter jasmine, forsythia, Weigela, rose etc. groundcover plants can be selected, Oxalis, clover, iris, lily, and other suitable varieties of Zephyranthes candida.

\subsection{Pay attention to the Division and Connection of the Landscape Area, and Embody the Details Beautifying of the Landscape}

The plants on the enclosure or transition region of the local landscape, achieve reasonable space and connection of the park site, to solve the problem of transition of landscape lack of loose, the floor cypress, forsythia shrubs such as corner part of buildings and roads were softened for near pieces and sculpture show available plant landscape collocation for background, the field corner bare loess is added to plant grass, in the area of regional large flower planting turf block was, form a certain pattern, enrich the visual effect for exposure of transformer equipment or equipment room with dense bamboo or enclosed shelter.

\subsection{Attach importance to the Embodiment of Plant to the Human Nature Space}

Considering people walking and sitting rest, planting large trees crown in different regions for providing shade, enjoy the scenery line in the visitors with rest facilities to form enclosed or semi enclosed private space utilization and landscaping plants, were isolated for noisy or hidden danger area available to plants. The exhibition area in different landscape, using plants with historical and cultural background and related poetry used to emphasize the theme of landscape plants, in the wide area can form a plant theme park, while the rich contents feel certain garden culture atmosphere.

\section{Conclusion}

The Daming Palace site park is a key project for the construction of Xi'an city and the protection of large sites. It is also a card for the future city of Xi'an. Scientific and reasonable planning and protection of Daming Palace site, combining greening and cultural heritage protection, enhancing the ecological effect of sites and surrounding environment, enhancing the landscape effect of the site environment, constructing plant community landscape and reflecting the local characteristics. Xi'an City should protect the Daming Palace Ruins, do the site of the park landscape planning. It not only embodies the "The Belt and Road" core city construction characteristics, but also plays a good effective way of "city cultural tourism center".

\section{Acknowledgement}

The paper is supported by Xi'an Social Science Planning Fund named Research on the protection and landscape planning of Xi'an large site Under the strategy of "Belt and Road Initiative" (Code: 161N05).

\section{References}

[1] Zhu Haixia, Quan Dongji. Greats Sites Conservation and Regional Development Management in the Context of Urbanization [J]. China Soft Science, 2014(2): 161-170. 
[2] Chen Zeqiang, Liu Yan. Protection of the Ruins in the Urbanization Process: A Case Study of Tang Daming Palace Ruins [J]. Value Engineering, 2015(20): 45-47.

[3] Du Chunlan, Yao Weili. Landscape Planning for the Conservation and Interpretation in Large Heritage Site-A Case Study of the Suitang City in Luoyang [J]. Chinese Landscape Architecture, 2010(10): 38-42.

[4] Xiao Ailing. Study on the Protection Methods on Tang's Daming Palace Site [J]. Research on Heritages and Preservation, 2016(3): 18-29. 